\title{
THE ROLE OF THE RESEARCHER'S EPISTEMOLOGY IN MATHEMATICS EDUCATION AN ESSAY ON THE CASE OF PROOF
}

\author{
Nicolas Balacheff \\ CNRS \\ Laboratoire d'Informatique de Grenoble, France
}

\begin{abstract}
Author version of: Balacheff N. (2008) The role of the researcher's epistemology in mathematics education: an essay on the case of proof. ZDM International Journal of Mathematics Education. 40 (3) 501-512

Abstract: Is there a shared meaning of "mathematical proof" among researchers in mathematics education? Almost all researchers may agree on a formal definition of mathematical proof. But beyond this minimal agreement, what is the state of our field ${ }^{1}$ After three decades of activity in this area, being familiar with the most influential pieces of work, I realize that the sharing of keywords hides important differences in the understanding. These differences could be obstacles to scientific progress in this area, if they are not made explicit and addressed as such. In this essay I take a sample of research projects which have impacted the teaching and learning of mathematical proof, in order to describe where the gaps are. Then I suggest a possible scientific programme which aspires to strengthen the research practice in this domain. Eventually, I make the additional claim that this programme could hold for other areas of research in mathematics education.
\end{abstract}

\section{INTRODUCTION TO AN EPISTEMOLOGICAL DISCUSSION}

Is there a shared meaning of "mathematical proof" among researchers in mathematics education? There is a common expectation that almost all researchers will agree on a formal definition of mathematical proof, but beyond that what is the state of our field? No one would be surprised to find differences, and some might even see this as richness in a domain and a sign of dynamism in the community. In my opinion we must be more cautious with such an issue. The scientific challenge of research in mathematics education is not to develop opinions and beliefs about teaching and learning, but to shape a body of knowledge which should be robust (which means theoretically valid) and relevant (which means instrumental for practitioners and other stake holders). Convergence should be the rule. It must be our priority. Divergences must be considered as symptoms of problems, either theoretical or methodological, to be addressed by the community. However, by "convergence" I do not mean a unique system of thought. I mean that differences must be explained and related in a way which keeps coherent the overall understanding we have of processes and phenomena related to the learning and teaching of mathematical proof. To look at proof from a mathematical or a psychological perspective, or from a logical or socio-linguistic perspective, may lead to different statements, but what is important then is to relate these differences so as to explain the nature of proof in order to keep the integrity of the object we study (which is what it is, despite the variety of the lights theories and ideologies shade on it...) and to ensure the practical relevance of research. Currently the situation of our field of research is quite

\footnotetext{
${ }^{1}$ I first raised and discussed these issues on the occasion of the Taipei International Conference "Understanding Proof and Proving to Understand" (16-19 November 2002), on the invitation of Professor Fou-Lai Lin.
} 
confusing, with profound differences in the ways to understand what is a mathematical proof within a teaching-learning problématique but differences which remain unstated. This essay initiates an investigation of the diversity of the approaches. The attempt is modest, just trying to get a first insight about the current state of our field. It is based on three decades of work in this area, with some familiarity with the most influential pieces of work. Preparing it, I read again a number of articles or conference communications questioning them to figure out their epistemological rationale ${ }^{2}$ beyond the keywords they appear to share.

Before going ahead, I would like to make a basic remark: rationality is dense everywhere in human being life, either at an individual or a collective level. By "rationality" I mean the system of the criteria or rules mobilized when one has to make choices or decisions, or to perform judgements-indeed, a large part of our life has to do with informing, claiming, discussing, arguing. These rules and criteria could either be taken for granted and remain implicit (what is in general the case in the so-called every-day life), or they could be explicit or even formalized (what is the case when one has to justify his or her claim for the truth or the validity of a statement or an action). These rules and criteria could originate in opinions, beliefs or knowings ${ }^{3}$ but in all cases they are organized in a structure, which allows reasoning and decision-making. Searle (2001) notices that between knowing and deciding, as well as between deciding and acting, there is a gap and he proposes that it is rationality that allows human beings to fill in this gap. This is a very large understanding of rationality, but it holds the advantage of witnessing the complexity to which we are confronted.

Rationality is then the ground of any proving process. How we see rationality in general, and its relation to mathematics in particular, is a key point for our understanding of any piece of work in our field of research. One may accept, with not too much difficulty, that proving depends on content and context. Indeed, the issue of truth or validity cannot be settled in the same way in everyday life, in law, in politics, in philosophy, in medicine, in physics or in mathematics. One does not mobilize the same rules and criteria for decision-making in every context in which one is involved.

How do we take into account the tangle of context and content? The way we answer these questions determines our view of what a mathematical proof is from a teaching-learning point of view. The way we choose to answer these questions, either consciously or not, speaks for our epistemology of proof and for our own rationality.

Our epistemology of proof (the relationship we have with truth and validity) first shapes our research framework, even before the choice of a problematique (i.e. the choice of the relevant questions and research problems), and the choice of a theoretical framework and its related methodology. I do not see that this issue has been addressed, in my best knowledge, although to be aware of it and to explore it systematically may be what conditions both the quality of what we produce and the possibility to exchange results. My claim is that our own epistemology of proof is the first thing to decipher and to cope with, when entering our research field. One may easily agree that this is especially crucial for young researchers, who generally enter the field with a "naïve" or "intuitive" problématique. Actually, this is a concern for the whole field: until we have clarified precisely what the problem is like and how it limits our capacity to share research outcomes, it will be hardly possible to make significant progress in the field.

This essay is organized around a selection of projects though the objective is not as much to cover the literature in an exhaustive manner, but to point to contrasts between related approaches. The projects I have selected have proved to be influential in our domain; they form a sample which is sufficient for my purpose.

\footnotetext{
${ }^{2}$ This has been the key point of the lecture I gave to the $\mathrm{XI}^{\circ}$ summer school of didactique des mathématiques (Plestin-Les-Grèves1999) under the title "Preuve, démonstration et écriture mathématique (entre essai et synthèse)" (unpublished, power-point available)

${ }^{3}$ In this text, as we did in the translation of Brousseau work, I use "knowing" as a noun to convey the useful distinction we have in French, as in most roman language, between "connaissance" and "savoir" - the later being translated by "knowledge" in English.
} 
These projects illustrate five epistemological positions presented here in five different sections followed by a synthesis questioning the possibility of a consensus. These positions cover a significant range of possibilities which go from mathematical proof as a universal and exemplary type of proof (§2.1), to approaches considering mathematical proof to be of an idiosyncratic nature (case $\$ 2.2$ ), or considering mathematical proof at the core of mathematics (\$2.3) or as a tool needed by mathematics but that gets its meaning from applications (\$2.4) or being specific to mathematics as an autonomous field (\$2.5). Each section starts by a characteristic quotation followed by comments and analysis.

Eventually, one issue is present in all research on the teaching and learning of mathematical proof and cannot be separated from it: language. Proof, whatever is the meaning ascribed to this word, comes to existence only after a claim for validity of an utterance. Only once a statement has been articulated can one enter the process of validating it, proving it, arguing about it, or justifying it. Language is at the core of proof and argumentation in general ${ }^{4}$, but especially in mathematics because of the non-physical nature of the mathematical objects. We will touch upon this issue of language in the last part of this essay.

\section{WINDOWS ON EPISTEMOLOGIES OF MATHEMATICAL PROOF}

\subsection{THE UNIQUE CONTRIBUTION OF MATHEMATICS}

"The concept of proof is one concerning which the pupil should have a growing and increasing understanding. It is a concept which not only pervades his work in mathematics but is also involved in all situations where conclusions are to be reached and decision to be made. Mathematics has the unique contribution to make in the development of this concept [...]" (Fawcett 1938 p.120)

The rationale of this quotation is that mathematics, because of its privileged relationships with logic, could be viewed as a reference to proving in general, and beyond as the best example of rationality. This understanding of mathematics has been widely shared, mathematics being the place for the education of deductive reasoning.

This seems to have been systematized in a rather radical way by the US mathematics educators of the first part of the last century. In his seminal book, "The nature of proof", Fawcett demonstrates how considering any claim, as for example the one presented here after (taken from Fawcett 1938 p.84), under the constraints of a representation format (a three columns table) favoring an analytical approach, may prepare students to understand the logical power of mathematics as a science of formal reasoning.

1. Racial superiority.

Many people believe that the white races are superior to the coloured races.

My present belief concerning this is:

\begin{tabular}{l|l|l}
\hline Analysis of my belief & $\begin{array}{c}\text { Statement of } \\
\text { the facts }\end{array}$ & Assumption \\
\hline & &
\end{tabular}

\footnotetext{
${ }^{4}$ Habermas makes very clearly this point in his essay about truth and justification (Habermas 1999, especially chapter 2 ).
} 
The idea is that the validity of a statement-either an opinion, or a belief, or a knowing ${ }^{5}$ - could be scrutinized with the help of such a format which could facilitate the elicitation of its rational. For mathematics education, the didactical object in line with this approach is the well-known two columns proof which facilitates the evaluation of a proof by both the student and the teacher (see Herbst 1999; 2002; also González and Herbst, 2006).

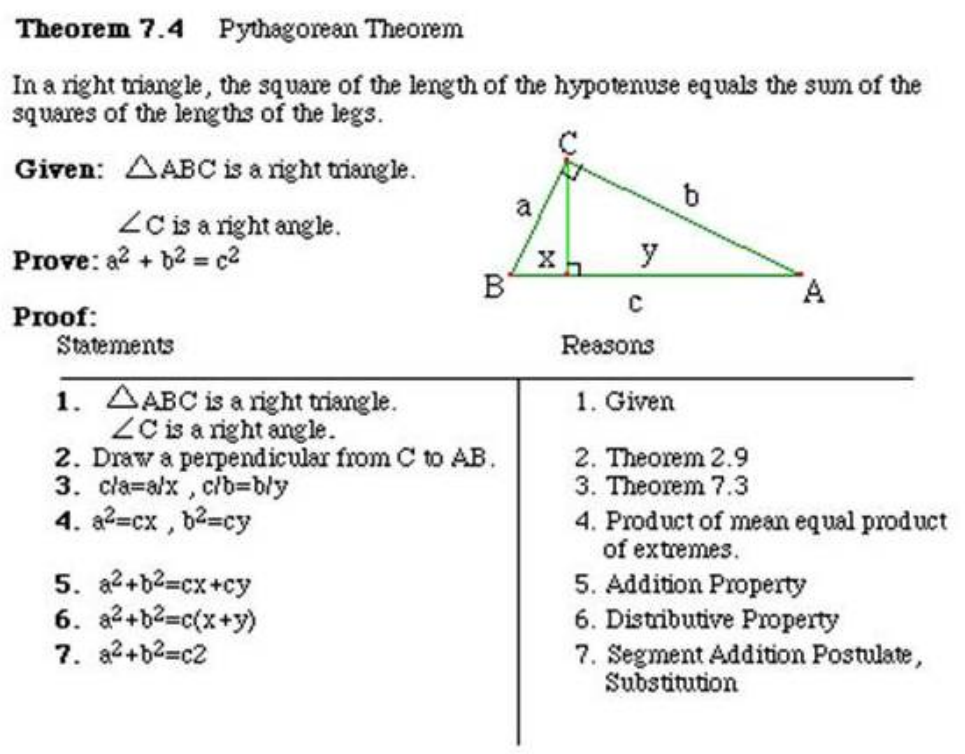

Example taken from Clemens S., O'Daffer P., Cooney T., \& Dossey J. (1994)

Geometry. Menlo Park, CA: Addison-Wesley. p.301

As it is very often the case, this process of didactification "killed" he initial intention of which Fawcett was a characteristic example ${ }^{6}$. But I leave to US researchers the responsibility to develop further this judgement. Herbst argues that,

"What was at stake was not just to teach for transfer but also to show that such transfer could be demonstrated. [...] The students' logical reasoning had to be measurable according to the standards of the measurement movement, and the two-column proof format could be adapted to furnish measurement instruments" (Herbst 1999).

The emphasis on the formal dimension of mathematical proof, reified by the two-column proof format, led to strong reactions in the last part of the $X X^{\circ}$ century. As Harel and Sowder point: "students do not learn that proof are first and foremost convincing arguments, that proofs (and theorems) are a product of human activity, in which they can and should participate [...] the goal is to help students define their own conception of what constitutes justification in mathematics" (Harel \& Sowder 1998, p.297). The radical reduction of mathematical

\footnotetext{
${ }^{5}$ Following what we did for the translation of Brousseau' theory of didactical situations, I will here use the word "knowing" to keep track of the difference we have in roman languages between connaissance and savoir; the latter being translated by the word "knowledge". A "knowing" is a personal construct, which becomes a "knowledge" if it is shared by a community under an institutionalised form.

${ }^{6}$ The two column form precedes Fawcett historically. His three column proposal was an innovation that never took hold. Fawcett wrote in 1936 and the two columns appeared in the 1910s (in US) apparently coming from UK (P. Herbst, personal communication).
} 
proof to its formal organization had a price that researchers have pointed out, which is the loss of the meaning of proving or at least a radical shift of this meaning-which likely was not intended by Fawcett or the proponents of other formats for proof writing. This criticism favored the raise of an awareness of the human dimension of any mathematical activity, and of proving in particular. It is on this line that Usiskin suggested that the teaching of proof had failed "because we too often ignore: when and why mathematicians do proof, the variety of possible types of proof, and how mathematicians write down proofs." (cited in Harel and Sowder 1998, p.419).

\subsection{IDIOSYNCRATIC NATURE OF PROOF SCHEMES}

"A person's proof scheme consists of what constitutes ascertaining and persuading for that person [...] As defined, ascertaining and persuading are entirely subjective and can vary from person to person, civilisation to civilisation, and generation to generation within the same civilisation" (Harel \& Sowder 1998, p.242). And finally: "one's proof scheme is idiosyncratic and may vary from field to field, and even within mathematics itself" (ibid. p.275).

Indeed, Harel and Sowder put back the person at the center of a problématique of proof in a rather drastic way. In their work, the characterization of proof schemes is based on careful definitions, which reinforces the central place of the individual as such (ibid. p.241):

- A conjecture is an observation made by a person who has no doubt about its truth. A person's observation ceases to be a conjecture and becomes a fact in his or her view once the person becomes certain of its truth.

- By proving we mean the process employed by an individual to remove or create doubts about the proof of an observation

- Ascertaining is the process an individual employs to remove his or her own doubt about the truth of an observation

- Persuading is the process an individual employs to remove other doubts about the truth of an observation

In a way, understanding proof is viewed as an element on a continuum - which is of a genetic nature-from the more "idiosyncratic" to the more "objective", which is the more specific to mathematics as a content which transcends human beings' specific ways of knowing. Harel and Sowder, after others, suggest a classification that gives account of this view, ranging from "ritual" and "authoritarian" to "structural" and "axiomatic". 
The following chart summarizes this:

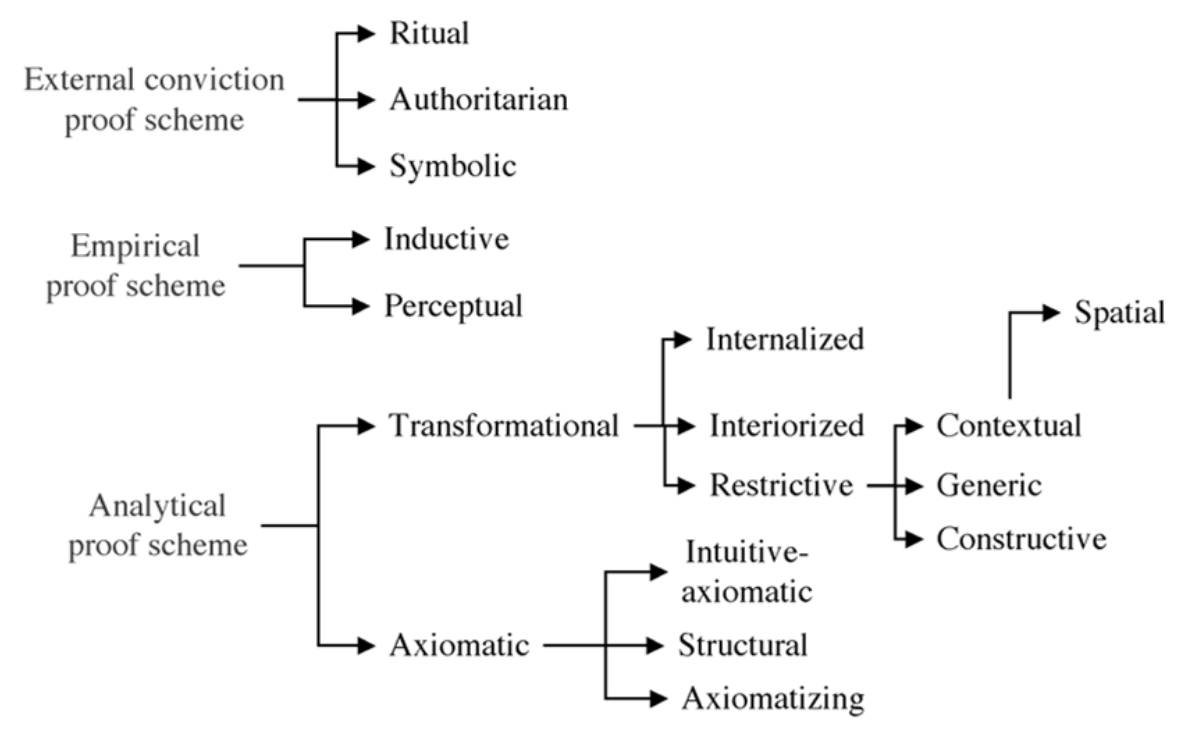

It must be kept in mind that this classification is based on an exploratory study. Its strength lies in the fact that it is not abstract, nor a priori. As stated by Harel and Sowder: "all [results] were derived from our observation of the actions taken by actual students in their process of proving" (ibid. p.244). The word "actual" in this quote is symptomatic of these researchers position. It refers to a naturalistic approach; an approach which intends to be free from the artificiality of an experimental setting. Moreover, these researchers insist that there is no normative hierarchy in the proposed classification. It is what it is. It is what observation delivers.

The focus on the person does not mean that the content is forgotten. It appears here and there, like in the analysis of a student's conception of a definition of a line, which points this student inability to represent the geometric properties stated by the teacher-experimenter, in any context but his own imaginary space (the case of Duane, pp.269-270). The possible role of a specificity of mathematics is in particular taken into account when defining the axiomatic proof scheme: "when a person understands that at least in principle a mathematical justification must have started originally from undefined terms and axioms, we say that this person possesses an axiomatic proof scheme" (ibid. p.273).

Interactions in the classroom, viewed through the lenses of this approach, encompass all the complexity of the confrontation of individuals' - and a priori acceptable-proof schemes in the teaching of mathematics. The following two excerpts attest to it. On the student side:

"Bob expresses his dissatisfaction with the instructor's decision by saying that he does not understand what difference it makes if he was told the proof or if he found it on his own; the result in both cases is the same: he would know the proof" (ibid. pp. 247-248).

And on the teacher's side:

"during instruction, empirical justification serve as examples of arguments given by mathematicians, and may inadvertently sanction the empirical proof scheme as a mode of justification fully acceptable in the mathematical context" (ibid. p.278).

In this approach, the word "theorem", although specific to mathematics (insofar as this word is a typical word of the mathematical jargon), gets a psychological meaning. This meaning is illustrated by the authors' claim that a theorem is for a mathematician (i) a statement understood for which nothing suggests that it is not true, 
(ii) and which is significant enough to have implications in various domains and hence justifying a detailed study; (ii) eventually, its author has an outstanding reputation in the domain of the theorem, and (iv) there exists a convincing argument for it, rigorous or not, of a known type.

\subsection{PROOF, THE HEART OF MATHEMATICAL THINKING}

"Proof is the heart of mathematical thinking, and deductive reasoning, which underpins the process of proving, exemplifies the distinction between mathematics and the empirical sciences" (Healy and Hoyles 1998 p.1).

The London group carried out one of the largest and most comprehensive study investigating students' understanding and views of mathematical proof. They made this study with in background a strong claim about the nature of proof in mathematics. This view of mathematical proof is primarily related to the technical understanding of what it is in the mathematical activity:

"The process of building a valid proof is clearly a complex one: it involves sorting out what is giventhe mathematical properties that are already known or can be assumed-from what is to be deduced, and then organizing the transformations necessary to infer the second set of properties from the first into a coherent and complete sequence." (ibid.)

In the context of the UK National Curriculum for mathematics, the investigation they carried out focused on the following items:

- To describe the characteristics of mathematical justification and proof recognized by high-attaining Year 10 students;

- To analyse how students construct proofs;

- To investigate the reasons behind students' judgements of proofs, their performance in proof construction and their methods of constructing proofs.

This study started in 1995. It involved good grade 10 students and their teachers. Students were asked to construct proofs or to judge proofs using questionnaires and interviews ${ }^{7}$. They obtained detailed results, which altogether demonstrate rather low levels of achievement in the construction of proofs, with better success in algebra than in geometry. But the same analysis demonstrates that most students understand the generality of a valid proof: students are better at recognizing a valid argument than at constructing it, and their conception of proof and of its role is key in their performance. These performances appeared independent of the teacher characteristics but highly related to the number of hours devoted to mathematics, the explicit emphasis on proof and the level of students (grade or familiarity with the content at stake).

One of the general results emphasized by Healy and Hoyles (1998) stresses the need for a more explicit teaching of mathematical proof:

"The research indicates that the ability to construct, assess or choose a valid proof is not simply a matter of general mathematical attainment. Clearly this has an influence, but at least some of the poor performance in proof of our highest-attaining students may simply be explained by their lack of familiarity with the process of proving. Far too many students have little idea of this process and no sense of proof, which, our findings suggest, can hinder their ability to construct and correctly evaluate proofs." (ibid. p.6)

\footnotetext{
${ }^{7} 182$ students in the pilote study, 2459 students queries form 94 classes in 90 schools.
} 
In short, first of all, the teaching of mathematical proof must not lead to an emphasis on the form, but on the meaning of proof within the mathematical activity. These researchers invite the community "to engage students with proof while discussing with them the idea of proof at a meta-level, in terms of its meaning, generality and purposes" (ibid. p.7) Rigorous mathematical proofs and informal argumentations are seen as possibly cohabitating, provided that they are considered within the common framework of a larger reflection on proving and its place and role in mathematics. This research and the conclusions drawn by the London group, to some extend support David Tall suggestion:

"The cognitive development of students needs to be taken into account so that proof are presented in forms that are potentially meaningful to them. This requires educators and mathematicians to rethink the nature of mathematical proof and to consider the use of the different types of proof related to the cognitive development of the individual" (Tall 1998 p.17).

\subsection{PROOF, AN INDISPENSABLE TOOL OF MATHEMATICS}

"The most significant potential contribution of proof to mathematics education is the communication of mathematical understanding" [...] "A mathematics curriculum which aims to reflect the real role of rigorous proof in mathematics must present it as an indispensable tool of mathematics rather than at the very core of that science" (Hanna and Janke 1996, pp. 877-879)

Hanna's and Janke's view of mathematical proof is rather instrumental, insisting on the fact that "in the first place, formal proof arose as a response to a persistent concern for justification [...] Formal mathematical proof has been and remains one quite useful answer to this concern for justification" (ibid. p. 888). The position they adopt is in clear rejection of a common fallibilist ideology of those who "appear to see proof in general, and rigorous proof in particular to help impose upon students a body of knowledge that it regards as predetermined and infallible" (ibid. p.890). They argue against a naïve view of rigor and certainty in mathematics. They support their argument by coming back to errors in the history of mathematics (ibid. p. 891), and to the current revision of proving standards required by the use of computers in mathematics (ibid. p. 881).

In reaction to the movement against mathematical proof-the so-called formal proof-they claim that "the use of proof in the classroom is actually anti-authoritarian" (ibid. p.891), and they even say that "it would be disturbing to see mathematics teachers ranging themselves on the side of a revolt against rationality" (ibid.). Hanna and Janke make then a pragmatic choice, expressed in the form of two hypotheses:

- Hypothesis 1: "Communication in scholarly mathematics serves mainly to cope with mathematical complexity, while communication at schools serves more to cope with epistemological complexity"

- Hypothesis 2: "In order to understand the meaning of a theorem and the value of its proof, students must have an extensive and coherent experience in the appropriate application area. This pragmatic foundation can and should be taught in conscious separation from the formal derivation. Only then the students be able to see the real point of a proof"

(Hanna and Janke 1993 pp. 433-4)

Although Hanna and Janke do not state anywhere that they answer Tall's 1998 demand, one can observe that their hypotheses are a first possible response, and that they are stated at an epistemological level. It is not the form of mathematical proof that they put under question, valuing any other format of proof instead of the mathematical one. They advocate the search for another relation between mathematical proof and mathematics as content. I see the epistemological complexity they point as a witness of the complexity raised by the specific nature of mathematical objects. But still the way proposed to address this complexity is to 
bypass it by constructing a systematic link between mathematics and its application fields. Eventually, one of the distinguished features of this approach of mathematical proof is the claim that,

"In particular proof cannot be taught or learned without taking into consideration the relationships of mathematics to reality" (Hanna and Janke 1996, p. 902)

\subsection{The foundational Unity of TheOREM, Proof AND THeORY}

"A geometrical fact, a theorem [...] is acceptable only because it is systematized within a theory, with a complete autonomy from any verification or argumentation at an empirical level" (Mariotti 1997, sec $1.3)^{8}$

Mariotti's claim contrasts in an important manner with Hanna's and Janke's position, since it purports not to search the roots of the meaning of mathematical proof primarily outside of mathematics ${ }^{9}$. Her position is clearly based on the recognition of a specific characteristic of mathematics: "the theoretical organization according to axioms, definitions and theorems, represents one of the basic elements characterizing mathematical knowledge" (Mariotti $1997 \mathrm{sec}$ 1.4).

Mariotti research programme must be situated within the general framework of the Italian approach to teaching and learning mathematical proof, which is based on two more general concepts: field of experience (a concept proposed by Paolo Boero-Boero et al. 1995) and mathematical discussion (a concept proposed by Bartolini-Bussi 1996).

- "Field of experience" ensures the presence of concrete and semantically pregnant referents for performing concrete actions that allow the internalization of the visual field where dynamic mental experiment are carried out, presence of semiotic mediation tools, construction of an evolving student internal context (conjecturing, arguing, proving take meaning there)

- "Mathematical discussion" refers to polyphony of articulated voices on a mathematical object. Mathematical discussion works as a lever to address two major issues: the need for proof, the distinction between argumentation and proof.

These concepts are related to the willingness to take into account two problems:

(i) The relation to content since proving is always stating the validity or the truth of a statement which has a content,

(ii) The relationship between proof and language, which is due to the dialogic nature of proof production (even if the person considers him or herself as his or her own interlocutor).

\footnotetext{
${ }^{8}$ Since this reference points to a document available on the web under un html format, I indicate here the section number instead of the page since the latter may vary from a browser to another.

${ }^{9}$ I must add that it does mean that Mariotti reduce mathematics to a formal game, on the contrary she relates it all along her work to problem solving likely to provide a "concrete meaning" to students activity. Her problématique is that of allowing students passing from a pragmatic to a theoretical conception of proving-hence proving getting its meaning from within mathematics.
} 
We must be aware of the Italian group claim of the need for the existence of a reference to proving as a system of shared principles and deduction rules. In other words, the basic equation shaping the Italian group's problématique for research on teaching and learning mathematical proof is:

$$
\text { theorem = system (statement, proof, theory). }
$$

In this theoretical context, the educational problem is to help students transition from the need of justifying to the idea of validating within a mathematical system ${ }^{10}$, and to recognize that the "acceptance of validation depends on the meaning of the rules and on the acceptance of the rules" (Mariotti $1997 \mathrm{sec} 4.4$.).

In this framework, the Italian group searches for the conditions that could allow students to access the meaning of theorems in mathematics (in fact, precisely, in geometry), and to study the mental processes at play. The observations, in experimental classrooms, lasted a long period and considered the whole school year at different grade levels $(5,8$ and 10$)$. The context is given by the study of shadows (e.g. the parallelism of the shadows of two non-parallel sticks). This context is chosen because shadows are "meaningful from the space geometry point of view; not easy to prove; and lacking the possibility of substituting proof with the creation of drawings" (ibid.). The teaching-learning setting covers several phases: to give a problem, to produce a conjecture, to discuss the conjecture, to work out its formulation and to prepare the proof. The role of teacher is seen as essential, and is emphasized in this approach: "The teacher is responsible for introducing pupils to a theoretical perspective which is needed for a systematic view of mathematical theorems" (Mariotti et al. 1997 $\sec 3)$

The results drawn from this experimental study include the following: "[Most students seem] aware of the fact that they had to get the truth of the statement by reasoning" (Mariotti et al. $1997 \mathrm{sec} 5$ ) and that "their reasoning started from properties considered as true and got the truth of the statement in the 'scenario' determined by the hypothesis" (ibid.). The research report draws our attention to the fact that "the whole activity performed by students in all the experiments shared many aspects with mathematicians work when they produce conjectures and proofs in some mathematics fields" (ibid.). Not only is mathematical proof-as an "object" - the referent, but also the mathematician activity reminding us that proving is a process.

A more comprehensive view of the problematique of this approach is conveyed by the authors' claim that "classroom culture is strongly determined by recourse to mathematical discussion orchestrated by the teacher to change the spontaneous attitude of students towards theoretical validation" (ibid.). For further discussions, I would personally like to emphasize in this quotation the use of the expression "theoretical validation", which in my own understanding capture the essence of the Italian group approach which tightly links proof, theorem and theory.

\section{QUESTIONING THE POSSIBILITY OF A CONSENSUS}

We use in our field of research a rather large number of key words, among which: proof, argumentation, justification, validation... but, for each of them, we have in mind slightly different meanings when taking mathematics as a reference. This is well known in the now classical exercise which consists of telling what the functions of proof are. The categories of functions of De Villiers, and of Hanna and Janke are often quoted; they are respectively (i) verification, explanation, systematization, discovery and communication, and (ii) construction of an empirical theory, exploration of the meaning of a definition or of the consequences of a hypothesis, imbedding a new fact in a new framework and allowing a new insight. I could add my own propositions, which I made at the very beginning of my work in our field (Balacheff 1987), or those of several

\footnotetext{
${ }^{10}$ Actually, I am here paraphrasing the following quotation: "[to pass] from the need of justifying towards the idea of validating within a geometrical system" (Mariotti 1997 4.2)
} 
other colleagues. In several cases the differences in understanding proof and its functions are more subtle and complex than one would have first expected.

Is a consensus possible? By consensus I mean at best a common theoretical framework, at least a glossary guaranteeing a minimal set of shared meanings. The deadlock on the route towards achieving such a programme is our own epistemology of mathematical proof. Epistemology means here the identification of an object and the web of the relations we establish around it with other objects, as well as problems, tasks and other possible activity involving it.

The examples selected for the purpose of this essay demonstrate the existence of radically different epistemologies. They correspond to very different understandings of mathematical proof from a teachinglearning perspective and hence they determine the choice of very different research programmes, research design and, above all, radically different understanding of what students produces or could produce.

Indeed, researchers themselves cannot avoid involving in their work their own epistemology of mathematical proof and, beyond it, their own epistemology of mathematics. The consequences to the communication of research are obvious; hence we must be aware of the differences among these epistemologies and of their implications on sharing theories and methods, problems and results. Not being considered seriously enough, these issues could become an essential obstacle to making progress in our field of research. It is in this sense that the researcher's epistemology could turn into a lock very difficult to unlock or break .

Indeed there are common points, which may facilitate the search for common grounds. Among them we can notice:

(i) The acknowledgement that foundation of mathematical rationality, at least from a learning perspective, is built upon and against a kind of "common sense" rationality coined by historical culture, moral and religious adhesions, professional and social practices of a community;

(ii) The existence of deep relationships between argumentation and proof the nature of which is the object of a debate-proof should be considered under the light of both theory and practice;

(iii) The acknowledgement that mathematics as a content raises specific difficulties either to be bypassed or on the contrary to be built in the emergence of a meaning of mathematical proof;

(iv) The acknowledgement that the teacher plays a key role either as a contingent distractor or a required facilitator.

Among all these issues, surprisingly, one does not show up: the relation between proof and language, proving and writing a proof. This is surprising first because-as shortly evoked in the introduction of this essay-proof is tightly related to language and discourse. Second, because from a practical point of view, teachers report often on both the difficulty that students have with the mathematical technicalities of a proof, and their mastery of its linguistic features (structure of the text, syntax and logic, etc.) Before concluding, I would like to briefly consider some aspects of the state of the domain from this perspective.

\section{COMPLEMENTARY REMARKS ON LANGUAGE AND PROOF}

Let us first mention a very basic remark by Pierre Amiet in his preface of a book on the history of writing. Amiet (1982) emphasizes that writing was drastically different from signs-even complex signs-since the aim of writing was not only to reify thoughts, but discourse itself with all its nuances captured in the norm of each language $^{11}$. Indeed, as one can easily realize, mathematicians do not write what they speak. While

\footnotetext{
${ }^{11}$ My free translation.
} 
mathematicians produce mathematical texts, it is not clear that they produce discourses-with all the reserve that a non-specialist must take in claiming so.

Exploring the relationship between language and proof, two dimensions emerge rather clearly: the textual dimension, which is more questioning the text as an object, and the interpersonal dimension, which is more questioning the existence and role of the author. Raymond Duval and David Pimm are for many years two good representatives of each these orientations of research. I ground this complementary remark on their work and contributions to the field.

\subsection{TEXTUAL DIMENSIONS OF PROOF}

Deductive reasoning holds two characteristics, which oppose it to argumentation. First, it is based on the operational value of statements and not on their epistemic value (the belief which may be attached to them). Second, the development of a deductive reasoning relies on the possibility of chaining the elementary deductive steps, whereas argumentation relies on the reinterpretation or the accumulation of arguments from different points of view. (Following Duval 1991, esp. pp. 240-241)

In order to understand Duval claim about mathematical proof, it is necessary to have in mind his definition of "semiotic register" which provides both the theoretical and the methodological framework in which he considers mathematical proof:

A semiotic register ...

- $\quad$ holds traces which can be recognized as the representation of something;

- $\quad$ provides rules of transformation to produce new representations which could serve to create new knowledge;

- provides rules for conversion towards another system of representation to make explicit other significations;

- $\quad$ provides rules of conformity in order to allow the construction of units of a higher level.

This characterization allows a study of the functional role of writing in the course of the construction of a mathematical proof. This does not mean that mathematics is reduced to language, but that the specific character of writing in mathematics has consequences on understanding it and beyond, on understanding mathematical proof. Aside the structural properties, the ternary step (hypothesis, theorem, conclusion) and the recycling of statements in order to link two steps (the conclusion of a step becomes the input of another one), this approach has been used to shape some of the differences between mathematical proof and argumentation. This shaping emphasizes two features of deductive reasoning. On the one hand the peripheral place of the epistemic value of statements (whether you more or less trust them)-recognizing that mathematical proof is apodictic by essence, and on the other hand a kind of computational character of deductive reasoning. This demonstrates that in Duval's sense argumentation and proof are of a radically different nature. One can imagine how this should raise question in our field considering that other researchers give a central role to "mathematical arguments" and "mathematical argumentation" in their consideration of what proof is.

Duval's approach should be contrasted with the approach of David Pimm (1987). This author, quoting Halliday, recalls that a register is "a set of meanings that is appropriate to a particular function of language, together with the words and structures which express these meanings" (ibid. p.75). And Pimm adds: "Registers have to do with the social usage of particular words, ways of talking but also ways of meaning" (ibid. 108). 
Following Halliday-as Pimm does-one can consider that the function of a text cover "ideational aspects" (express content), "interpersonal aspects" (interaction between the author and the reader) and "textual aspects" (coherence and autonomy). So, if the focus of Duval is on the "textual aspects", the focus of Pimm is rather on the "interpersonal aspects". The latter is especially evident when, referring to Stubbs, Pimm remarks that "the potential use [by teachers] of registers as territorial and status marker rather than as essential to the accurate or concise expression of mathematical ideas" (ibid. p.109)

So, even considering the issue addressed in this paper from the very specific point of view of language, one can see an important discrepancy between the two possible underlying epistemologies of proof. I establish this contrast in the next section.

\subsection{INTERPERSONAL DIMENSIONS OF PROOF}

"The conventions of mathematical writing are neither necessary nor natural consequences of the nature of the subject matter; they are rather 'the product of current relations of power and discourse practices'(Clark and Invanik 1997 p.14) within the community" (Burton and Morgan 2000 p.450)

This understanding of mathematical writing drives Burton's and Morgan's analysis of a corpus of 53 articles written by 70 mathematicians, in which these researchers trace the presence of the author, the expression of authority (negative or positive), the identification of a territory and of a knowledge domain. Finally, the results presented are essentially convergent with the statement by Clark and Invanik: "Writing, for both students and researchers, is not just about communicating mathematical subject matter. It is also about communicating with individual readers, including powerful gatekeepers such as examiners, reviewers and editors. The writer needs to know how to write in ways that are likely to convince such readers that he or she has the authority to write on this topic, that the subject matter is important enough to be interesting, and that paying attention to what is being said is worthwhile" (ibid. p.451).

Morgan (1998) carried out an extensive research on students' writings in the context of the UK GCSE examination, which allows us to realize the consequences of this view on research on teaching and learning mathematics. For the GCSE examination, students have to write "substantial reports of their work on mathematical investigation". But contrarily to Fawcett emphasis on the benefit from formatting reasoning, the idea there is to privilege as far as possible access to the underlying understanding of the content and to the richness of the process in a kind of naturalistic manner. The aim of a text in mathematics is viewed as a means to act upon readers, to persuade them. It should be analyzed first from the point of view of argumentation (ibid. p.10). A basic hypothesis is that: "the written (or oral) text is assumed to convey the intention of the author, without distortion or alteration, into the mind of the reader" (ibid. p.196). But again, like in Fawcett's case, since students' writings are assessed in the context of an examination, the original intention cannot avoid being distorted by its didactification. Morgan explains and demonstrates well this phenomenon which could be seen as the consequence of a double bind introduced by the didactical contract:

- Emphasis on the sincerity of the expression of the student, but what is in the end evaluated is not the product but its author.

- Emphasis on the research process, but the evaluation eventually privileges the content demonstrated.

The literature supporting students and their families' efforts, and which so to say implements the didactification of students' writings, is rather explicit in this sense: "Examine the mathematical content of your work. If the mathematics is merely adding up, then do not expect to gain more than a grade that reflects that you can add up!..." (Morgan quotation, ibid. p.64); or: "You must not be tempted to generalize if it is beyond your ability. It is very easy to spot someone who has tried to generalize without understanding what is involved." (ibid.) 


\subsection{LANGUAGE, AN ISSUE TO BE FURTHER EXPLORED}

Proof and language are tightly related, especially in mathematics ${ }^{12}$. It is then not surprising to find in research that privileges language the same type of discrepancy as the one we find in research that addresses mathematical proof directly. Halliday's dimensions of a text (ideational, interpersonal, textual) cannot be separated the one from the other in the actual text, and the same is likely to apply when taking the researchers perspectives. However, research frameworks make clear and apparently exclusive choices, either focusing on textual aspects (§4.1) or interpersonal aspects (§4.2). This has an impact on the results obtained and the related statements they suggest about teaching. This has also consequences on the possibility we have to take benefit from them, and to capitalize their outcomes either to make progress or to make sense of new problems.

\section{CONCLUSION}

Arsac (1988) asked the question: "Is it possible to teach mathematical proof?" The answer is nowadays unanimously affirmative. But, it is not clear that we all understand in the same way that question and its possible answers. On the contrary it seems that research speaks in a very confusing way about this topic. Some years ago, an ICMI Study asked the key question "what is research in mathematics education, and what are its results?" I remember not feeling very comfortable with this question and with what we could say about it. The case of proof, as I sketch it in this essay is a good illustration of the reasons that made me critical at that time with the way we addressed the issue raised. To be efficient and fruitful, research in mathematics education should pay attention to its coherence across all the specific research projects constituting it. Taking a few cases as I did here for the sake of the argumentation, does not limit the generality of my claim; all the studies considered are influential and can be considered paradigmatic of the different approaches.

This essay illustrates the importance of the role played by the researcher epistemology in his or her choice of a problématique, and his or her choice of a theoretical background and its related methodology. How is it possible to go beyond a mere report of the differences? How is it possible to organize the study of the relationships between "truth" and "validity" within a society, a culture, and the constitution of a didactical problématique of mathematical proof-that is, a problématique of mathematical proof from the point of view of teaching and learning. How does the rationality of the researcher interfere with or support the research in which he or she is involved? Which role does his or her view play in judging the acceptability of criteria to decide, choose or judge a mathematical activity taken from a learning perspective? How does that relate to proving?

\footnotetext{
12 One may oppose to this statement the case of "proofs without words"; I will not address it here-I did it for the 1991 summer school in didactique-but I can ensure that considering this issue does not change drastically the claim insofar as mathematics is concerned (and not just its popularization).
} 
From a recent reading of Jürgen Habermas (1999), I keep the suggestion that rationality has roots of three different nature: the predicative structure of knowing, the teleological structure of action and the communicative structure of discourse. All these roots are tightly related, in other words one may not be able to take one into account without considering the two others. I saw a difficulty of this nature when I claimed that validation, communication and the nature of knowing cannot be separated in our attempt at understanding what is proving all about. I summarized it in a table as the following:

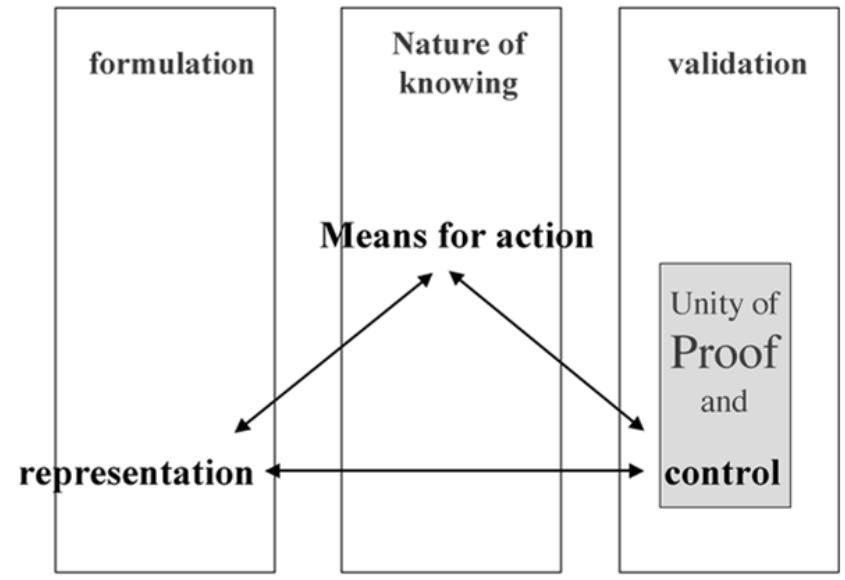

\begin{abstract}
This diagram represents the relationships I proposed in an earlier publication $^{13}$ in which I tried to understand the complexity of students' understanding of what proving could mean. I was not aware at that time that "control" is a key concept in constructing the unity of problem solving and proving that Boero has extensively explored. Pedemonte's work clarifies this issue and offers a possible way to solve the problem raised (Pedemonte 2002).
\end{abstract}

Would it be possible, recognising the systemic organisation of the relationship between representation (the communication level), knowing (the epistemic ${ }^{14}$ level) and control (the validation level), to connect our research outcomes-and beyond them, our problématiques and theoretical frameworks? My belief is that this should be possible, provided that each of us try to locate his or her own approach among the possible ones, and make the effort to propose an understanding of his or her results from a different perspective.

A stronger organization of our research practice should include the following items to be recommended to the community, especially project leaders and PhD students. Here they are:

- A common lexicon and related definitions possibly acknowledging differences related to our different languages, culture, institutions

- $\quad$ The elicitation of the different problématique and their possible contrast and relationships

- The elicitation of theoretical commonalities and divergences, and possibly turn them into questions

- $\quad$ Comments on the different methodologies, their benefit and possible limits

\footnotetext{
${ }^{13}$ Balacheff 1987, p.160.

14 I take here epistemic in Piaget sense, that is: "the carrier of knowledge" (in either a social or an individual sense as Furth 1969, p.193, emphasises).
} 
- The acknowledgement of accepted results or turn objections and differences into research problems

- The invitation to replicate studies or their results and to develop formatted comparisons of results (something like a benchmark).

Research in mathematics education in the coming decade should be passing from childhood to maturity. We need an organisation of our work at an international level, beyond our idiosyncratic views or possible tendency to accept ready-made ideas. This must surely be the case for mathematical proof, which is critical to any teaching or learning project in mathematics. The task is particularly difficult but not out of reach. It does not mean the building of a sort of flat consensus, but an acknowledged awareness of what connects and what separates our work. In the end, I have every expectation that the benefit of this effort will not be only for research, but significantly for teaching and learning in everyday classes insofar as it will finally be possible for teachers and mathematics educators to make sense of what we publish and claim.

\section{ReFERENCES}

Arsac G. (1988) Les recherches actuelles sur l'apprentissage de la démonstration et les phénomènes de validation en France. Recherches en didactique des mathématiques. 9(3) 247-280.

Amiet P (1982) Introduction historique. In: Naissance de l'écriture. Paris: Réunion des Musées Nationaux.

Balacheff N. (1987) Processus de preuve et situations de validation. Educational Studies in Mathematics 18(2) 147-176.

Bartolini Bussi M. (1996) Mathematical Discussion and Perspective Drawing in Primary School. Educational Studies in Mathematics 31(1/2) 11-41.

Boero P., Dapueto C., Ferrari P., Ferrero E., Garuti R., Parenti L., Scali E (1995) Aspect of the MathematicsCulture relationship. In: Procedings of PME XIX, Recife vol. I, pp.151-166.

Burton L., Morgan C. (2000) Mathematicians writing. Journal for Research in Mathematics Education 31(4) 429-452.

Clark R., Ivanik R. (1997) The politics of writing. London Routledge.

Duval R. (1991) Structure du raisonnement déductif et apprentissage de la démonstration. Educational Studies in Mathematics 22(3) 233-263.

Fawcett H. (1938) The nature of proof. The National Council of Teachers of Mathematics Thirtheenth Yearbook. New York: Bureau of Publications of Teachers College, Columbia University.

Furth H. G. (1969) Piaget and Knowledge. Theoretical foundations. NJ: Prentice-Hall.

González G., Herbst P. (2006) Competing Arguments for the Geometry Course: Why Were American High School Students Supposed to Study Geometry in the Twentieth Century? International Journal for the History of Mathematics Education 1 (1) (Open Access Journal http://journals.tclibrary.org/index.php/hist_math_ed)

Habermas J. (1999) Wahrheit und rechtfertigung. Frankfurt: Suhrkamp (French translation: Vérité et justification. Paris: Gallimard, 2001).

Hanna G., Janke N. (1993) Proof and application Educational Studies in Mathematics 24(4) 421-438.

Hanna G., Janke N. (1996) Proof and proving. In: Bishop A. et al. (eds.) International handbook of mathematics education (pp. 877-908). Dordrecht: Kluwer Acad. Pub.

Harel G., Sowder (1998) Students' proof schemes: Results from exploratory studies. In: Schonfeld A., Kaput J., and E. Dubinsky E. (eds.) Research in collegiate mathematics education III. (Issues in Mathematics Education, Volume 7, pp. 234-282 ). American Mathematical Society.

Healey L., Hoyles C. (1998) Justifying and proving in school mathematics. Summary of the results from a survey of the proof conceptions of students in the UK. Research Report Mathematical Sciences, Institute of Education, University of London.

Herbst P. (1999) On proof, the logic of practice of geometry teaching and the two-column proof format. The Proof Newsletter 
<http://www.lettredelapreuve.it/Resumes/Herbst/ Herbst99.html>.

Herbst P. (2002). Establishing a Custom of Proving In American School Geometry: Evolution of the Two-Column Proof in the Early Twentieth Century. Educational Studies in Mathematics 49, 283-312.

Herbst P. (2002) Engaging students in proving: a double bind on the teacher. Journal for Research in Mathematica Education (33)3 176-203.

Mariotti M.A. (1997) Justifying and Proving in Geometry: the mediation of a microworld. Revised and extended version of the version published in: Hejny M., Novotna J. (eds.) Proceedings of the European Conference on Mathematical Education (pp.21-26). Prague: Prometheus Publishing House.

<http://www.lettredelapreuve.it/Resumes/Mariotti/ Mariotti97a/Mariotti97a.html>

Mariotti M. A., Bartolini Bussi M. G., Boero P., Franca Ferri F., Rossella Garuti M. R. (1997) Approaching Geometry theorems in contexts: from history and epistemology to cognition. PME XXI, Lahti, Finland. pp.180-195

<http://www.lettredelapreuve.it/ Resumes/Mariotti/Mariotti97.html>

Morgan C. (1998) Writing mathematically (the discourse of investigation). London: Falmer Press

Pedemonte B. (2002) Etude didactique et cognitive des rapports de l'argumentation et de la demonstration dans l'apprentissage des mathématiques. PhD thesis. Université Joseph Fourier de Grenoble (France) and Genova University.

Pimm D. (1987) Speaking mathematically. Communication in the mathematics classroom. London: Routledge and Kegan Paul.

Searle J. (2001) Rationality in action Boston: MIT Press.

Sekiguchi Y. (2000) Argumentation and Mathematical Proof in Japan. The Proof Newsletter <http://www.lettredelapreuve.it/Newsletter/000102Theme/000102ThemeUK.html>

Tall D. (1998) The cognitive development of proof: is mathematical proof for all or for some. Paper presented at the UCSMP Conference. Chicago University.

Browse also the bibliography of The Proof Newsletter: http://www.lettredelapreuve.it 